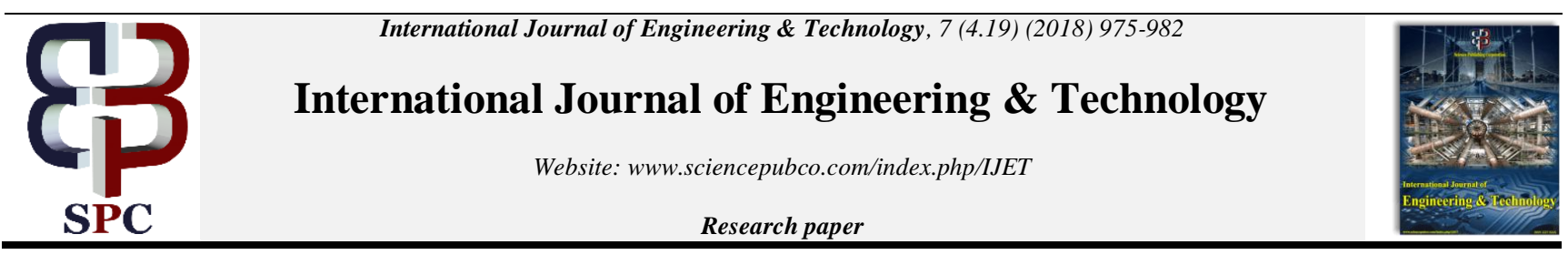

\title{
The Virtue Role in the Sustainability of Architecture
}

\author{
AlaaJaafarHasan ${ }^{1}$, Abdullah Saadoon SalmanAlmaamori ${ }^{2}$ \\ ${ }^{1}$ Engineer, Master student of Technology University / Department of Architecture \\ ${ }^{2}$ Assist.Prof, University of Technology / Department of Architecture \\ *Corresponding author Email: ' alaajafar10@yahoo.com
}

\begin{abstract}
Until man reaches the moderation, it must reform itself and its activities as the infrastructure of society. Since his inception on the basis of moral virtues It also help him to move towards society, thus achieving human development which in turn achieves sustainability. The research addressed virtue as an integral part of morality, from it began the teachings of religion and showed the relationship between him and his environment Based on the concept of moderation to achieve sustainability.

the Search attempt to discuss the absence clear imagination of virtue concept and its role in architecture sustainability, so The research aims to clarity the role of the concept of virtue in the permanence of the architecture and its survival on the assumption that virtue has a role in the sustainability of architecture. To achieve this aim the research used Inductive methodology (descriptive, analytical) through election samples and Test, finally Take virtue into consideration in the design process Contributes to the sustainability of the building Conversely in the event of negligence, it may lead to outbreaks of vices and the factors of violence and theft that cause the abandonment of the building is The most important results.
\end{abstract}

Keywords: Ethics, virtue, moderation, environment, sustainability, development.

\section{Introduction}

There is a lot of clarification of the meaning of the virtue and interpretation of some of them prepared as ethics, there is no difference between them and is referred to by the Ghazali and some see it is the smallest part of morality, which begins with the structure of the individual itself to generalize and reach the construction of a society and the achievement of a whole city virtuous, which refers to Plato and some of them is morals is the creation Practical in virtue as it is with Ibn al-Khatib. As a result of the expansion of the concept and its implications, but there is a collective agreement that virtue begins with the individual and contribute to its construction, and if that is done, is the establishment of a virtuous society and a virtuous city based on security and stability, which in turn leads to its sustainability. In the Islamic religion, sustainability has been addressed not in its explicit verbal meaning, but in terms of its meanings, in terms of the Islamic religion, represented in the earth and its creatures in water or on land and its phenomena such as mountains, plateaus, rivers and the atmosphere surrounding them to provide a healthy environment for humans. The lack of clarification of virtue in a brief or implicit manner in the sustainability of architecture, made the importance of research lies in clarifying it; On the assumption that virtue has a role in the sustainability of architecture so the research will focus on the purpose of achieving its objectives to address the concept of virtue and moderation and sustainability in the framework of knowledge in the first axis. The second axis will focus on building the theoretical framework and extract the most important vocabulary from the previous architectural studies and chock. the third axis is represented in elected projects for implementation. Finally, the fourth axis represents the most important conclusions reached was the absence of virtue in the design process contributes to the abandonment of buildings, in turn, the decay of its sustainability..the research used Inductive methodology (descriptive, analytical).

\section{1.The First Axis: Cognitive Framework for Research}

The concept of virtue will be addressed in the first axis to clarify the role of virtue and its philosophy in the sustainability of architecture.

1.1.1. The Concept of Virtue is Linguistically and Synthetically:

Fidelity and favoritism: the rest of the thing. Virtue and virtue: the best thing. (Jamal al-Din Abi al-Fadl Muhammad, 2005, p. 602) and the virtue of the thing in the sense of his or his job or the purpose of his own or his own (IbnMnzar, p. 527)we deduce from the past that virtue is charity and the perfection of the individual.

Philosophical concept of virtue: Aristotle pointed out that it is the avoidance of the parties and the necessity of the center (Abdul Aziz Bin Abdullah, 1983, p. 53). He also defined it as a natural or acquired readiness to do deeds that correspond to good and must be met because they do not fulfill their purpose. (Muhammad Abdaljabri, 1998, p. : 81-83), while Ibn al-Khatib believes that morality (practical creation by virtue) is a stage of Sufism, as the know-how must go beyond the temples of limping from one to the other to accommodate houses and stages and characterized the three stages and degrees of differentiation and Islam and faith and tenderness and with the closure of records It is present in all of them with its qualities associated with the beginnings of the States and Alfouath goals do not obscure the combination of the 
difference is not broken creation right here Arif up to serve as witnesses in a place of mysticism and morality because of Mahmoud Aref becomes a mirror in which reflected existence. (Abdulaziz bin Abdullah, 1983, pp. 100-101)Descartes is like a man with a bow who, for the sake of happiness alone, shares both happiness and virtue, and a goal of virtue has struck both. (Abdul Aziz bin Abdullah, 1983)Philosophical virtue is a necessity of the middle leading to happiness according to the Sufi doctrine, while the other doctrines are seeking the perfection of the thing and its perfection.

Procedural definition of virtue Is the medium in the thing without excessive or approaching it, which begins in turn the structure of the individual himself and then rise to perfection.

1.1.2. Types of virtue and levels: There are two types of virtue, which is negative and positive, the negative aspect is the resistance to sin and rejection, but the positive is the work of good. https://st-takla.orgIbn al-Khatib was interested in kindergarten negative virtues such as asceticism and trust, which does not send the owner to adventure in the field of life as much as it means positive and practical virtues such as courage and courage and diligence and pursuit. (Abdulaziz bin Abdullah, 1983, p. 55) and that virtue has three levels of individual, social, and spiritual. Some may choose one level and others may combine the other and a few improve behavior at the three levels and some may behave at these three levels wisely. https://st-takla.org

1.1.3. Mothers of Virtue: That the mothers of virtues at alGhazali are wisdom, courage, justice, chastity and wisdom. It is from the moderation of these four origins that the beautiful morality is derived from the power of reason, moderation, good faith, integrity of integrity and integrity of measure and understanding of the minutes of things and deviation with the increase and deceit and deception and deviation with diminishing and foolish. (Ghazali, 2012, pp. 166-167)

The theories were divided into the theory of the mind and the theory of conscience. Plato's theory of mind is that of the Fittagorean doctrine, which is a gentle, divine soul descended from its upper world and imprisoned in its physical body. Because of the element of divine self and its exemplary virtue during its last life in two worlds, where nostalgia remained in the world of happiness, which tasted of its pleasure, it aspired to perfection, aspired to goodness and sought to emulate the world of ideals. , Where intelligently the individual recognizes the importance of exchange (exchange of benefits and harm with the environment). (Dr. NazmiOdeh, Dr. Mahmoud Khalil, p. 7) As for the theory of conscience, Percy, who in turn corresponds with Ibn al-Khatib, argues that there are two types of morality, a kind that sows the value of duty under the pressure of society, so that the sum of the social returns that affect our will is the structure of duties. The second type is due to a psychological factor and a sentimental factor, The manifestations of the championship and the memories of the virtues and heroes. (Abdulaziz bin Abdullah, 1983, pp. 4446 )Ibn al-Khatib sees that there are degrees of perfection or types where the first type is social perfection, which comes from a material smell that has limits if it is transformed into a decrease. The second type has a share of the social color but its base can be a fundamental element of virtue in the Muslim and Roken In the mystic, which is represented as the piety and that if achieved justice organized and tranquility in existence is a moral perfection, while the third is the perfection of the mystic, which is the end of degrees MtjalMajali and the swell. (Abdul Aziz bin Abdullah, 1983, pp. 74-75)Note from the above the importance of the individual (human) and its interaction with the surrounding environment and reflected from the benefits or harmful to the environment or it.

\subsection{Human and Environment According To Islamic Perspective}

God created the universe, including all of its beings and all of them, a man's treasure to worship and order the earth, and sent messengers missionaries and human beings carrying the approach that governs the relationship between people on the one hand and between man and the environment on the other.(Yunus, 2003, p. 28) where man becomes part of the ecological system not only materially but spiritually more deeply.(Edwards \& du Plessis, 2001, P.17)

The merit of man is measured by the degree of his ability to develop the earth and its ages. The Almighty says in SuratHud verse 61That indicates that the architecture of the land is a mandate from God Almighty. From an Islamic perspective, the relationship between man and the environment is based on two principles: harnessing and moderation. (Maha al-Zubaidi, BahgatShahin, 2008, p. 76).

Harnessing: Is to harness the Creator to the components of the environment in order to help man to perform his mission in the reconstruction of the earth, saying Almighty in Surat Ibrahim verses (32-33).(Maha al-Zubaidi, BahgatShahin, 2008, p. 7)

Mediation: This avoids the reality of man's position in the universe. Man is a master in the universe and not the master of the universe, as some thinkers in the West see it. . (Yunus, 2003, p. 28) God did not create man until he controlled the capabilities of the universe but to be a patron of earth's resources. (Edwards \& du Plessis, 2001, P.19)

$\mathrm{He}$ also created an ecological balance where He Almighty created everything in this universe by the scale and the scale. The increase in the object is offset by a deficiency in something else, and this increase and deficiency is for the great wisdom of the balance of the universe and its stability.(Balochi, 1994, p. 155)

\subsection{Vices}

Ibn al-Khatib al-Ghazali sees that vice is a deviation in virtue to the point of increase or decrease and exaggeration or abandonment. The virtue of courage emanates from its deviation with reckless excess, arrogance, greatness and wonder, and its deviation with decreasing humiliation, humiliation, smallness of breath and weakness.Ibn al-Khatib al-Ghazali also called for the removal of the filthy morals, which are repugnant to the essence and the essence of it. The vices are the With anger and lust and tongue lesions (Abdulaziz bin Abdullah, 1983, pp: 120_121_122_123_124_125_126_128_129)(and laziness

\subsection{Sustainability}

Design and construction of buildings with minimal environmental impact, including all phases of design, material selection and construction, including building analysis and energy efficiency. (Laura L.Bames, 2014)

- a concept that is called the diverse biological environment of living organisms, and factors that maintain their existence for as long as possible. By adapting to the environment through the exploitation of natural resources for a longer period of time leading to the maintenance of continuity of life.http://mawdoo3.com

-Is a study of how natural systems work, diversity and produce everything the natural environment needs to remain balanced. http://www.maan-ctr.org

As a result of the increasing depletion of natural resources and increased pollution led to imbalance in the environmental balance leading to a decline in the ability of nature in self-renewal and continuity of maintaining the quality of life and survival and continuity. Many sustainable efforts have emerged as a dogma and sanctuary for sustainable development whose purpose was to address these sources of threat.Sustainable development is therefore defined as a way of living governed by human ethical frameworks and a developmental pattern that aims to create a society with a tendency to be less generous with a change of dominant cultural concepts about the future of normal life. (Ahmed AwadJuma, Siham Abdel Halim Mohammed, 2017, p. 
657)Which deals with issues of social justice, environmental quality and quality.(SaqniFakiyeh, MoisiBelaid, 2010, p. 40)

1.4.1. Sustainability and the Environment in the Islamic Perspective: Many Islamic norms have emerged in order to preserve the environment from the orientations of the Holy Quran and the Sunnah of the noble Prophet to individuals and groups urging them to clean and take responsibility and order and not to waste, and to keep away from all who pollutes the individual and society. The concept of the environment has been linked to the concept of the environment and its preservation and protection from all forms of pollution. It cannot be separated from the ethics that a Muslim must adhere to in all his daily behaviors and relations with the surrounding components of the environment and its elements. (Yunus, 2003, p. 23) It is clear from the above that the individual and the environment in the event of interaction with each other, in turn lead to the creation of sustainability

Procedural definition of sustainability It is all what is done as a result of the interaction between man and his surrounding environment and his survival in a balanced manner.

1.4.2. Sustainable Human Development : That sustainable human development has multiple dimensions and elements (eg equality and cooperation, empowerment, sustainability, productivity, cultural component, spatial) Interact with each other as a result of the dialectical relationship between them, including: the humanitarian component, the human, social, environmental, economic and political security, poverty reduction and sustainability, while emphasizing the centrality of man as an active actor in the development of society through his active participation. This, in turn, enhances human dignity and respect for its rights.

It is worth noting that the basic elements of sustainable human development are the mothers of virtues, which are represented by the equality that aims at achieving justice in the use of wealth for present generations without affecting future generations. This in turn is only the virtue of human beings, which urges them to cooperate to achieve equality and justice. Physical and other aspects that are intended to preserve and develop them.

\section{Theoretical Framework}

A series of literary and architectural studies will be taken for the purpose of extracting a number of the main and secondary vocabulary referred to by the studies to crystallize the floor and construct the vocabulary of the theoretical framework, which is considered the first stages of solving the research problem and studies are :

\subsection{Study (Zaki Mubarak, 1924) (ethics at Ghazali)}

Al-Ghazali does not differentiate between the word of virtue and creation, and he has a body of the soul and its inner image. The basis of virtue is due to what he took from Aristotle, where he took the theory of mediation called moderation and opposed to some of the virtues do not have a fair, for example, but against one, and the opposite of injustice. And some about Plato as a similar theory and also the theory of compatibility. Zaki believes that the virtues are divided into negative and positive, but for the Ghazali is often negative. And the virtues divided by Zaki to individual and social, including the owner of the same as the conviction, for example, they are individual, but those that need to deal with people, such as the Secretariat, for example, social, and sees that Ghazali me of individuality. As for the vices, it is not limited by the definition of its own particular, but it is excessive in virtue or negligence. It is always recommended to take off the bad and inculcate morality.

In terms of dealing with the arts, he pointed out to avoid the manufacture of embossing and drafting and construction of buildings plaster and the collection of decorating the world, all hated by the people of religion. But he did not have a single word about decoration and construction where he later said (Do so of those who have many is not haraam, because the decoration of the correct purposes, and the mosques are still adorn and embossed doors and ceilings, although the inscription of the door and the roof is useless but just adornment so role). We conclude from the previous study the importance of moderation resulting from fairness, and the importance of inscriptions and decorations in the study is often criticized and sometimes Medhat will be based on the medium use buildings.

\subsection{Study (Dr. Maha Al-Zubaidi, Dr. BahjatShahin, 2008) (Principles of Sustainability in Traditional Architecture according to Islamic Perspective)}

The researchers pointed out that the teachings of the Islamic religion include many principles of sustainability with the social organization and human behavior of the community, which reflected on its output on the urban output, both on the standards of the features of traditional architecture or urban and planning communities of cities derived from the content of the teachings of the Islamic religion being the law of religion and the lower society. Where they pointed out that the Islamic religion referred to the environment not in its literal sense, but in its concept of living organisms and land and its living on land or in water and its manifestations on the surface, such as the plains, mountains and others and their atmosphere, which contains many elements that help to preserve life on The earth's surface. We conclude that the Islamic religion with its moral orientation at the level of social organization and human behavior helped to include sustainability in its various principles, which achieved continuity of architecture with its material aspect at the level of the building in particular and the city in general.

\subsection{Study (D. Mishari bin Abdullah Al-Naim, 2009) (Architecture Makarem ethics)}

The architecture of Islamic civilization is based on (Makarim ethics), not the component and the material achievement because morality is a moral part that is formed slowly and quietly and permeates the material achievement and prints it by its nature. The Prophet (peace and blessings of Allaah be upon him) was the guardian of the neighbor, and he identified the ways of the road, so that the authority to harm the road is charity, there is a moral aspect that prompts the members of the Muslim community to adopt these literature and adopt them as a basis for the development of the urban environment. The moral system is profoundly reflected in the sense that it constitutes the societal value and gives the material forms so that it is the key to understanding the architecture of the Islamic civilization, which must be understood to restore the spirit of the city.

The second idea is the development of the state institutions that have created new jobs. The Arab city of Salameh has become entangled and its functions have expanded with the development of social, political, economic and judicial institutions. These direct functions formed the material fabric of the city and created clear utilitarian meanings. But until the city had an Islamic character, Islamic morality had to be penetrated into the fabric in order to be printed by its nature. The third area is the architecture of Makarim ethics, which makes the symbolic meaning of the deep value because it is related to the method of use, which expresses the human presence and not the physical product. The city was formed to express the moral aspect. The analysis of the Arab city in the Islamic civilization will prove that the material fabric was a direct reflection of ethical systems Deep. The study explained that ethics is the basic component of the forms of forms, ie the physical aspect of architecture (Islamic architecture) and make it durable, based on three basic areas have been explained previously. 


\subsection{Study (Abdin, Nano, 2012) (concept of virtue in the term city)}

The concept of virtue followed the cornerstone of society, which was torn by the wheels of events in the 19th and 20th centuries and the techniques were in control at the beginning of the twentyfirst century. He is interested in building his research in achieving the goal of reaching the highest level of human perfection, by addressing the concept of the city in an old style and methods and tools needed by the modern city. More than the need for technologies and economic possibilities and planning expertise to complete the development process and development procedures. Leading to the arrival in the call to work virtue virtue of being the key to solving all the problems of the city and the base of reform and organizational processes. Virtue is one that shapes and guides, and techniques are achieved by achieving perfection and thus solving the world's obstacles in terms of organization and reform.

\subsection{Study (Dr. Ali Thawini, 2013) (ethics, religion and architecture)}

Ethics is the material half of the essence of religion, and became a science and a branch of philosophy studying the biography of man and the nature of right and wrong. The biography of the person, his personality, his values and his duties are directed towards himself and other society. There are three orientations to the interpretation of morality:

1- Theory of Relativity: which claims that right and wrong depends on the culture of society, what is right in a society may be wrong in another society.

2- Theoretical theory: claims that there are objective standards of truth and error can be discovered and applied to any human being is the ideal way.

3- Self-theory: All moral standards What are the questions have to do with taste or opinion

In modern times there has been an interest in the philosophy of morality by the stream of rationalism represented by Descartes, Leibniz and Spinoza, the latter suggesting that man must be satisfied satisfactorily in a world driven by determinism.

Because man is a cell within the fabric of society, he must establish an organic relationship between them which entails rights, duties and a way of treatment. Because the architect is an individual in society, he must have these qualities because he has the power to organize and legislate for the affairs of that community. It paints a highly sensitive ethical methodology in which honesty, honesty, frankness and clarity are practiced, and its sense of well-being is dispersed and it is distinguished in its goals. It thus confers privacy on the place and generality of society on public buildings and buildings. It also directs and invests the arts in order to attract the noble beauty of man's manners and manners to his ethics, which, in the framework of a sincere approach to dealing with time and space, serve as flexible, flexible and organic as the growth and development of beings and societies are stable, dedicated and faithful to the principles of morality. The letter referred to the tendencies of Tawil ethics and the role of the individual and the architect in particular being a component of the fabric in order to sensitize the relationship between what is practiced in the work and the welfare of his sense of differentiation between the ends he should give a private place and general public buildings to serve as goals and match with time and place able to adapt as living things but fixed Amina is dedicated to the principles of ethics.

\subsection{Study (Al-Sudair McIntyre, 2013) (after Al-Fadil - research in moral theory)}

The book deals with the moral issues in their different dimensions, which are the result of a number of principles based on the philosopher Almdair McIntyre to establish his discussions, his assessments and criticism of the virtue prevailing in his time and before his time:

1- Sociological principle: that the individual before the community.

2- Historical principle: It has been shown that morality belongs to history, or is related to history, and its virtues change from time to time, there is no absolute moral virtues.

3-The principle of teleposity (Telos): that is, the virtues of the goals intended for them and not arbitrary matters left to the individual or individuals and their whims and volatility.

4-Ethical principle: In the strict sense, the interest of society above all interest, the principle of Aristotle.

These principles formed the kind of hammer that came down from Macintyre to individual philosophies, from the first to the last, especially after the failure of the project of the Age of Enlightenment (Yhenlightenment). And the virtues are placed in three stages, represented in the first stage, which is related to virtues as qualities necessary to achieve internal good practices, and the second are qualities that contribute to the good of all life, and the third phase is linked to the pursuit of the good of human beings, A concept that can only be formulated and acquired from within the continuing social tradition of evolution. It is also mentioned that the practice of virtues is not of value in itself, but has a purpose and purpose, where we value and appreciate the virtues through our understanding of that goal and intent you cannot be brave or fair or anything else, without attention to those virtues for themselves. The three virtues are the first one after the virtues. The second is that these qualities all contribute to the good of all life. The third is related to the pursuit of the best of beings. So that virtue is a property cannot be acquired only from within the tradition of social continuity in development.

\section{7. (Sara Nabil, Thomas Plotz, David S.Kirk ,2017)( Interactive Architecture : Exploring and unwrapping the potentials of organic user interfaces)}

The organic user interfaces (OUIs) are flexible, efficient interfaces that are aesthetically pleasing, and each place can be moved as an integral part of everyday life. The research deals with interactive architecture on two levels: 1) architecture and landscape 2) Interior Design. Challenges emerged in terms of moral and behavioral formation when constructing internal and external designs that can change their shape or appearance dynamically independently or interactively. Where sensor environments in general are advanced systems that involve complex scenarios and are therefore vulnerable to "hacking" activities as well. Special security measures may be required to protect background or mobile furniture.

As a key step forward for OUI architecture, BIM was considered as a way to include security technologies in OUI programs not only to create anti-piracy systems but to identify who has the rights to interact - change - to the external and internal elements or interfaces. That these effects are applicable to any system designed, but the need to highlight this aspect because it requires new considerations that affect people in their own space. Another challenge is to design appropriate changes in the original architectural design and its potentially sensitive impacts on the population. In OUI engineering, materials, methods of sensing, stimulation and interaction will be an essential part of architectural design, requiring careful studies in each case to control and avoid any consequences that may be produced on families both physiologically or psychologically. The interior design of the building shows many challenges at different levels of moral, social and artistic aspects. The adoption of the BIM system takes into consideration the design of the appropriate variables in architectural design to suit the use of spaces of privacy to the users of the building and includes several levels of moral, social and psychological. 
Table (1-1): shows the main and secondary vocabulary of the theoretical framework (Source: Prepared by the researchers)

\begin{tabular}{|c|c|c|c|c|}
\hline main vocabulary & Secondary vocabulary & \multicolumn{3}{|c|}{ Possible values } \\
\hline \multirow[t]{10}{*}{$\begin{array}{l}\text { Principles of sustainability in the } \\
\text { architecture of virtue }\end{array}$} & $\begin{array}{l}\text { Planning and dealing with } \\
\text { the site }\end{array}$ & $\begin{array}{l}\text { Urban texture of the city organically int } \\
\text { paths of movement }\end{array}$ & grated frc & n blocks of construction, streets, \\
\hline & \multirow[t]{3}{*}{ Design Thought } & The middle courtyard & Closed & $\begin{array}{l}\text { Environmental, cultural, social, } \\
\text { aesthetic requirements }\end{array}$ \\
\hline & & \multirow[t]{2}{*}{ Misguided alleys } & \multicolumn{2}{|c|}{ Wall openings } \\
\hline & & & \multicolumn{2}{|c|}{$\begin{array}{l}\text { Thick walls and delusions connect the } \\
\text { central courtyard }\end{array}$} \\
\hline & \multirow[t]{3}{*}{ Means of natural ventilation } & \multicolumn{3}{|l|}{ Pedicure (air fresheners) } \\
\hline & & \multicolumn{3}{|l|}{ The openings } \\
\hline & & \multicolumn{3}{|l|}{ The middle courtyard } \\
\hline & \multirow{3}{*}{$\begin{array}{l}\text { Environmental design and } \\
\text { energy conservation }\end{array}$} & \multirow{2}{*}{$\begin{array}{l}\text { Exploitation of the components of the } \\
\text { natural and geographical environment }\end{array}$} & \multicolumn{2}{|c|}{ Use of passive energy } \\
\hline & & & \multicolumn{2}{|c|}{ Renewable energy sources } \\
\hline & & \multicolumn{3}{|c|}{$\begin{array}{l}\text { Building materials based on their adaptation to the social values and customs and } \\
\text { traditions of society }\end{array}$} \\
\hline \multirow{2}{*}{$\begin{array}{l}\text { Levels of Achieving Virtue for } \\
\text { Architecture Sustainability }\end{array}$} & \multirow[t]{2}{*}{ BIM system } & \multicolumn{3}{|l|}{ Change in appearance } \\
\hline & & \multicolumn{3}{|l|}{ Change the shape of the internal elements } \\
\hline \multirow{4}{*}{$\begin{array}{l}\text { The dimension of virtue in the } \\
\text { sustainability of architecture }\end{array}$} & Sociological principle & \multicolumn{3}{|l|}{ The individual before society } \\
\hline & Historical principle & \multicolumn{3}{|l|}{ The virtues change according to history } \\
\hline & $\begin{array}{l}\text { The principle of teleposity } \\
\text { (Telos) }\end{array}$ & \multicolumn{3}{|l|}{ Use of virtue to achieve an end } \\
\hline & A moral principle & \multicolumn{3}{|l|}{ Community interest first } \\
\hline
\end{tabular}

\section{Application}

Projects were selected for different time periods and for different countries to show that the difference in dealing with virtue in the design process or neglect, in turn affects the sustainability of buildings. The research will focus on some vocabulary in the measurement process as follows: First principles of sustainability architecture of virtue in terms of design thinking of the central courtyard and means of ventilation and environmental design in terms of materials. Second, the levels of achieving the virtue of sustainability of architecture through change in appearance. Thirdly, the exclusion of virtue in the sociological principle and moral principle.

\subsection{Abu Dhabi Sea Towers Project by AEDAS Architect}

The design was based on the desire to build a historic building that would reflect the cultural traditions of Abu Dhabi Emirate. The project consists of two towers for a multi-storey residential building with a height of $145 \mathrm{~m}$, which was completed in June
2012. The building is controlled by the computer to respond to optimal conditions, linking these optimal building expressions with its cultural context. In terms of principles, the building used the enclosed courtyard, which is the inner gardens with four floors, repeated every 7 floors. In terms of ventilation, the structure used a dynamic aerodynamic structure block that helps the air flow more uniformly. Outside and when opening the windows in the outer shell of the building, the air flows smoothly in the spaces to provide them with fresh air. The extension of the cutters from the center of the building inside to meet the inner shell is used to provide suitable distribution corridors for air movement, In addition to the distribution of natural light in the building. As for the levels of achieving the virtue of the sustainability of architecture has been to change the external appearance depending on the environment to achieve the use of passive energy and the provision of privacy to users which has been achieved by Using computer programs. In terms of dimensions has been achieved Sociological principle, they worked to achieve the comfort of the individual first by avoiding the impact of the external climate hot and dusty.

Table (1-2): represents images of the Abu Dhabi Sea Towers project
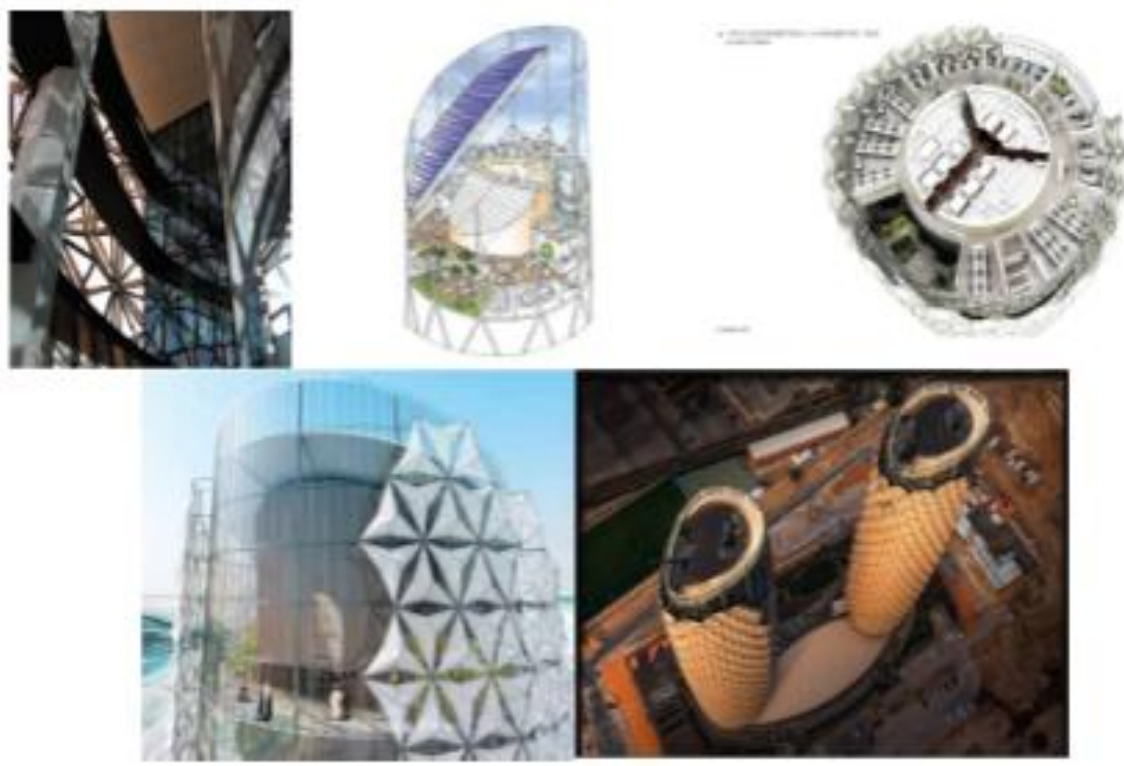
Table (1-3): Discussion and analysis of the results of the sea towers project

\begin{tabular}{|l|l|l|}
\hline $\begin{array}{l}\text { Principles of sustainability in the architecture of } \\
\text { virtue }\end{array}$ & Verification \\
\hline Principles of thought & The yards & A closed yard used for environmental purposes, consisting of repeated gardens every 7 floors \\
\cline { 2 - 3 } & Ventilation & $\begin{array}{l}\text { Through the openings (form Mashrabiya) in addition to the role of gardens as a museum as } \\
\text { well. }\end{array}$ \\
\cline { 2 - 3 } & Environmental Design & $\begin{array}{l}\text { Exploitation of environment components / using self-reactive materials } \\
\text { Building materials / reflective of the development of society }\end{array}$ \\
\hline $\begin{array}{l}\text { Levels of Achieving Virtue for Architecture } \\
\text { Sustainability }\end{array}$ & Verification \\
\hline Using computer programs & Change the external appearance according to the environment and to provide privacy as well. \\
\hline $\begin{array}{l}\text { The dimension of virtue in the sustainability of } \\
\text { architecture }\end{array}$ & Verification \\
\hline $\begin{array}{l}\text { Sociological principle } \\
\text { To achieve the comfort of the individual first, by avoiding the impact of the external climate hot } \\
\text { and dusty on the occupants. }\end{array}$ \\
\hline
\end{tabular}

\subsection{Local example / Baghdadi House}

The origins of the House of Baghdadi extend to the Sumerian House, which is the product of the Mesopotamian civilization, which has been an advanced model that is inextricably linked with the environment, the environment and construction techniques, and developed over thousands of years until it reached Basra and Kufa to the shape of the Baghdadi House today. The sky through the open spaces, thus realizing the first principles of the principles of sustainability in the architecture of virtue and it contains the openings in the windows used in the facade of houses to pass ventilation and lighting and contain air fresheners to get rid of excess heat and provide clean air for the health of the For local residents, local materials such as wood were used to make this $\mathrm{Al}-$ Shanashil suitable for the community. In terms of levels, the establishment of Chenashil in terms of dimensions and the size of openings varies from climate to another to control the amount of air and lighting in force into the house. In terms of dimensions, they worked to achieve the comfort of the individual first, by avoiding the impact of climatic conditions on him and to achieve privacy through the opening of the external openings and the use of the openings in the first floor and reduce openings in the ground floor in order to prevent honor from inside the house.

Table (1-4): Represents pictures of Baghdad houses

(20)

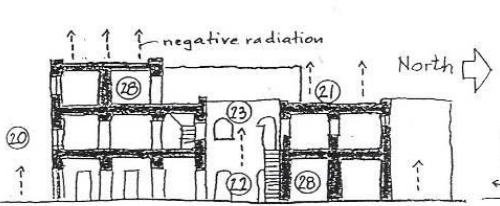

MIDNIGHT

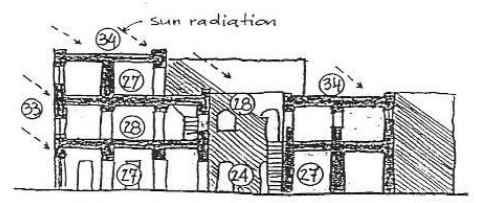

MID-MORNING



BEFORE SUNRISE

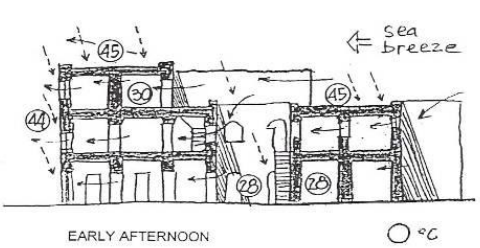

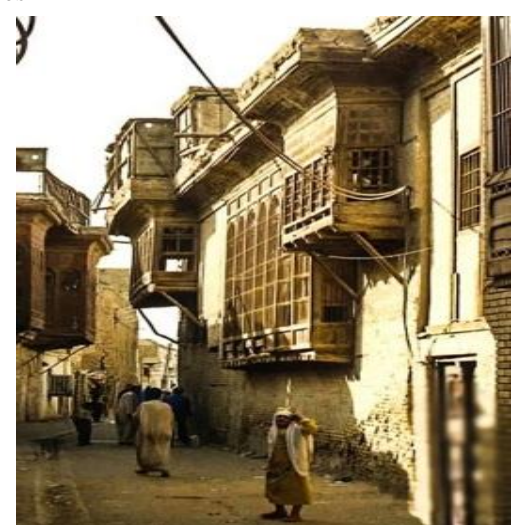

Table (1-5): Discussion and analysis of the results of the Baghdadi House

\begin{tabular}{|c|c|c|}
\hline \multicolumn{2}{|c|}{$\begin{array}{l}\text { Principles of sustainability inthe architecture } \\
\text { of virtue }\end{array}$} & Verification \\
\hline \multirow[t]{3}{*}{ Principles of thought } & The yards & An open courtyard, used for environmental, cultural, social purposes \\
\hline & Ventilation & $\begin{array}{l}\text { Through the openings in the Mashrabiya and the Baddakir, in addition to the } \\
\text { central courtyard }\end{array}$ \\
\hline & $\begin{array}{l}\text { Environmental } \\
\text { Design }\end{array}$ & $\begin{array}{l}\text { Building materials (bricks and wood) / suitable for social values and customs } \\
\text { and traditions of society }\end{array}$ \\
\hline \multicolumn{2}{|c|}{$\begin{array}{l}\text { Levels of Achieving Virtue for Architecture } \\
\text { Sustainability }\end{array}$} & Verification \\
\hline \multicolumn{2}{|c|}{ The computer software is not used } & $\begin{array}{l}\text { However, the different colors vary from climate to environment depending on } \\
\text { the surrounding environment and to provide privacy as well. }\end{array}$ \\
\hline \multicolumn{2}{|c|}{$\begin{array}{l}\text { The dimension of virtue in the sustainability } \\
\text { of architecture }\end{array}$} & Verification \\
\hline \multicolumn{2}{|l|}{ Sociological principle } & $\begin{array}{l}\text { To achieve the comfort of the individual first, by avoiding the impact of the } \\
\text { external climate and warm the provision of privacy and prevent the honor of } \\
\text { pedestrians on the users of the house as well }\end{array}$ \\
\hline
\end{tabular}

\subsection{Pruitt-Igoe scheme By Minoru Yamasaki}

In 1950, was designed for WWII fighter pilots in USA to shelter after being displaced in slums. Note the characteristics of the architecture of modernity in this project in terms of simplicity and simple box shapes, do not contain movement curves. The project consists of 33 buildings and 11 floors (2870 apartments), Contain lifts that stop at certain floors to force residents to use stairways and reduce congestion on elevators.

The project has only 600 people in 17 buildings because of the migration of its inhabitants, Violence in public places and gangs began. The project was demolished in 1972-1976.One of the reasons for the failure of the project was poor ventilation and the absence of central air conditioning systems, Stairs and narrow lanes have helped to attract thieves .In addition, the design was distanced man from his social and historical environment. 


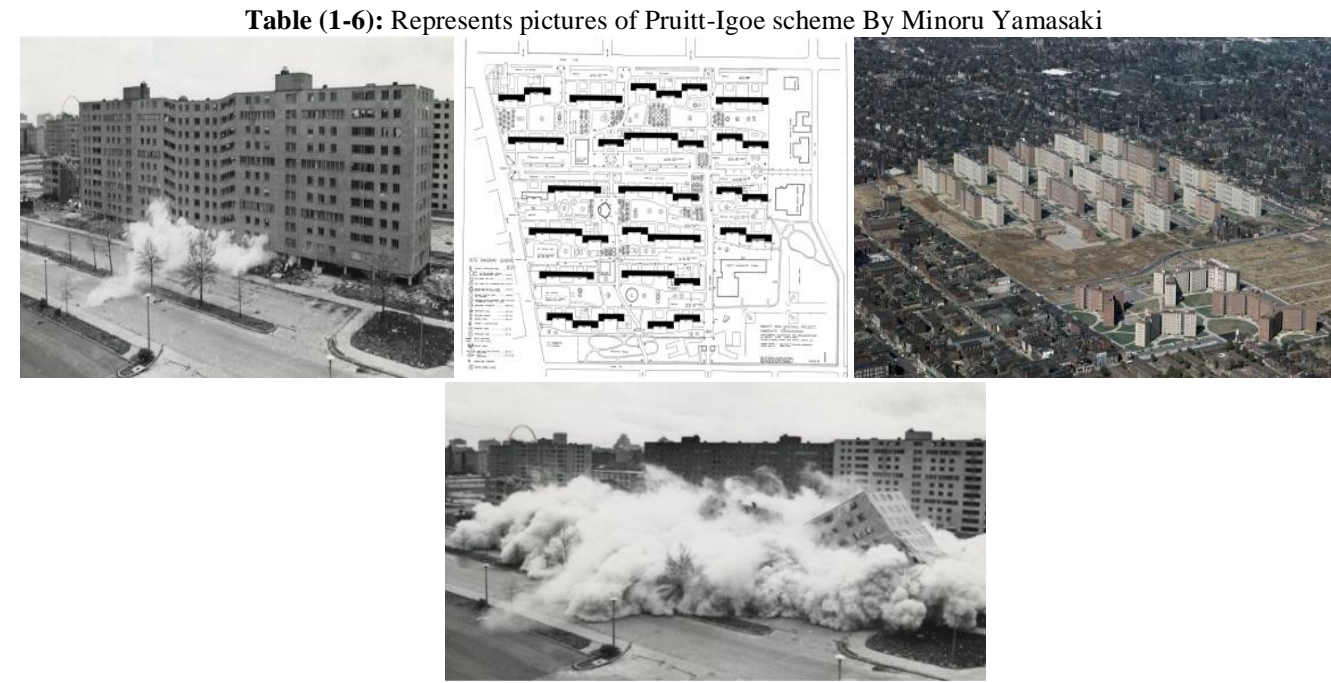

Table (1-7): Discussion and analysis of the results of the Pruitt-Igoe scheme

\begin{tabular}{|l|l|l|}
\hline Principles of sustainability in the architecture of virtue & Verification \\
\hline Principles of thought & The yards & does not contain \\
\cline { 2 - 3 } & Ventilation & It Did not achieve a good ventilation \\
\cline { 2 - 3 } & Environmental Design & $\begin{array}{l}\text { The building material and design was distanced man from his social and historical } \\
\text { environment. }\end{array}$ \\
\hline Levels of Achieving Virtue for Architecture Sustainability & Verification \\
\hline The computer software is not used of virtue in the sustainability of & Verification \\
\hline $\begin{array}{l}\text { The dimension of } \\
\text { architecture }\end{array}$ & Community interest first by The aim was to harbor the fighters. \\
\hline A moral principle
\end{tabular}

Table (1-8): Demonstrates the application of the main and secondary vocabulary of the theoretical

framework to the selected projects :Yes $=3$, maybe $=2$, no $=0$

\begin{tabular}{|c|c|c|c|c|c|}
\hline \multirow[t]{2}{*}{ main vocabulary } & \multirow{2}{*}{\multicolumn{2}{|c|}{ Secondary vocabulary }} & \multicolumn{3}{|c|}{ possible values } \\
\hline & & & Pro.1 & Pro.2 & Pro.3 \\
\hline \multirow[t]{5}{*}{ Principles of sustainability in the architecture of virtue } & \multicolumn{2}{|l|}{ The yards } & 3 & 3 & $\mathbf{0}$ \\
\hline & \multicolumn{2}{|l|}{ Ventilation } & 3 & 3 & 2 \\
\hline & \multicolumn{2}{|c|}{ Environmental Design } & 3 & 3 & $\mathbf{0}$ \\
\hline & \multicolumn{2}{|c|}{ The total possible values for each project } & 9 & 9 & 2 \\
\hline & \multicolumn{2}{|c|}{ The percentage achieved by each project } & $100 \%$ & $100 \%$ & $22 \%$ \\
\hline \multirow[t]{5}{*}{ Levels of Achieving Virtue for Architecture Sustainability } & \multirow[t]{3}{*}{ BIM system } & Change in appearance & 3 & 3 & $\mathbf{0}$ \\
\hline & & Change the shape of the internal elements & $\mathbf{0}$ & 3 & $\mathbf{0}$ \\
\hline & & Change the external interfaces & 3 & 3 & $\mathbf{0}$ \\
\hline & \multicolumn{2}{|c|}{ The total possible values for each project } & 6 & 9 & $\mathbf{0}$ \\
\hline & \multicolumn{2}{|c|}{ The percentage achieved by each project } & $66 \%$ & $100 \%$ & $\mathbf{0}$ \\
\hline \multirow[t]{5}{*}{ The dimension of virtue in the sustainability of architecture } & \multicolumn{2}{|c|}{ Sociological principle } & 3 & 3 & 2 \\
\hline & \multicolumn{2}{|c|}{ Historical principle } & $\mathbf{0}$ & $\mathbf{0}$ & 3 \\
\hline & \multicolumn{2}{|c|}{ The principle of teleposity (Telos) } & 2 & 3 & $\mathbf{0}$ \\
\hline & \multicolumn{2}{|c|}{ A moral principle } & 2 & 2 & 2 \\
\hline & \multicolumn{2}{|c|}{ The percentage achieved by each project } & $\mathbf{7 7 . 7 \%}$ & $\mathbf{8 8 . 8 \%}$ & $77.7 \%$ \\
\hline
\end{tabular}

\section{Conclusions}

1-Virtue in human action leads to sustainability both at the social and structural levels.

2-Virtue can make the individual perfect, and he aspires to sustainability by fulfilling all the needs of the individual and avoiding all the environmental factors and waste of energy.

3-That the medium represents not only environmental balance between the individual and the environment, but also between the traditional heritage and contemporary technology with different technologies and used in architecture by computer programs such as the BIM program, for example.

4-Sustainable development is based strongly on human virtues after the first (sustainable development) with elements similar to mothers (virtue).

5-That development does not occur only in the existence of human virtues to achieve justice between the current generation and the next, thus achieving the sustainability in all areas such as structural, economic and other.
6-That one of the reasons for the abandonment of buildings and not sustainable is that virtue does not take its role in the design process resulting in the chaos and spread of vices and the factors of theft and assault on users of buildings.

7-The development of the various structural and urbanism forms helps in finding solutions that are compatible with evolution in order to achieve privacy Construction.

\section{References}

[1] Al Quran al karim

[2] Al-Nawawi, Imam Abu ZakariaYahya, (2002), Riyad Al-Salheen from the Words of Sayyid Al-Mursaline, Al-Maarifah Foundation for Printing and Publishing, Beirut, Lebanon.

[3] Younis, Mohamed Ahmed Mohamed, (2003), Environmental Protection in Islamic Thought, Symposium on Culture and Science, Dubai, United Arab Emirates.

[4] Maha Al-Zubaidi, BahgatRashadShahin, (2008), Principles of Sustainability in Traditional Architecture according to the Islamic Perspective, Iraqi Journal of Architecture, No. 2 and Thirteen. 
[5] IbnManzoor, AbiFadl Jamal al-Din, "The Arabic Tongue", Dar Sader, Beirut, Lebanon

[6] NevinFargliBayoumi, (2016), Contemporary Applications of Morbidity as a Cultural Heritage, published research

[7] Al-Balushi, Fawzia Hassan, (2003),Environment: The Environment and Problems of the United Arab Emirates, Volume 1/42, C3, Culture and Arts Symposium, United Arab Emirates

[8] Zaki Mubarak, 2012, The Ethics of the Ghazali, Cairo

[9] NazmiOdeh, Mahmoud Khalil, The practice of students of the Islamic University in Gaza for some moral virtues and their relationship to some variables, (the year does not exist)

[10] Abdul Aziz bin Abdullah, (1983), Philosophy and Ethics at Ibn alKhatib, Dar al-Gharb al-Islami, second edition

[11] Ahmed AwadGomaa, Siham Abdel Halim Mohamed, 2017, Mechanism of Achieving Urban Sustainability through the UN Treaties Applied to Some New Egyptian Cities, Journal of Engineering Sciences.

[12] SaqniFakia, MoisiBelaid, 2010, Sustainable Human Development and Human Rights, Master Thesis, Farhat Abbas University - Setif Faculty of Law.

[13] LauraL.Bames,(2014),Green Building- Sustainable Building,Article

[14] Edwards,Brian\&Chrisna du plessis,(2001),Snakes in Utopia: a Brief History of sustainability, green Architecture: Architectural Design (AD), Vol.71,No.4,July 2001, Wiley-Academy,UK.

[15] David Morris,(2009), The Ethics Of Sustainability, on net,https://ilsr.org/presentation-ethics-sustainability/

[16] https://st-takla.org/Full-Free-Coptic-Books/His-Holiness-PopeShenouda-III-Books-Online/20-Makalat/1 AkhbarElYom/CopticPope-Articles-031-Virtue.html

[17] http://www.maan-ctr.org/magazine/article/1085/\%D9\%85\%D8\%A7 \%D9\%87\%D9\%8A\%D8\%A7\%D9\%84\%D8\%A7\%D8\%B3\%D8\% AA\%D8\%AF\%D8\%A7\%D9\%85\%D8\%A9-

\%D9\%88\%D9\%85\%D8\%A7 D8\%A3\%D9\%87\%D9\%85\%D9\%

8A\%D8\%AA\%D9\%87\%D8\%A7\%D8\%9F 